\title{
The grey area
}

\author{
Rheanna Bulten ${ }^{1}$ (D)
}

Received: 7 December 2021 / Accepted: 17 December 2021 / Published online: 5 January 2022

(C) The Author(s), under exclusive licence to Canadian Association of Emergency Physicians (CAEP)/ Association Canadienne de Médecine d'Urgence (ACMU) 2022

"How long until a pulse check?"

"30 s."

"Do we have a pulse?"

"No pulse."

"Ok, I'm going to call it, does everyone agree?"

"Time of death..."

When I was four years old, my little sister fell off a dock into Georgian Bay while we were looking for fish. She was two at the time. She had a life jacket on but fell face first and could not turn herself over. I called out and went running for my dad, and he pulled her out of the water. After some frantic breaths, she stopped coughing and calmed down. Having to act quickly and get the right help in that moment made the memory stick even into adulthood. There was a sense of loyalty to my sister, that she needed my help, and I would provide that help no matter what.

Now my sister is grown up, and I am a medical student working in the emergency room, where these situations happen often. Physicians must act quickly, get the right help, take initiative, and lead codes for patients of all ages. When someone is sick, no one in the room panics. There is an order and a calmness. We have algorithms to tell us when to do compressions, give epinephrine, and consider intubation. But on my most recent shift, I noticed a grey area in our algorithm. A moment where for a split second, I felt like I was four years old again, but this time it was not clear to me whether providing help was still the right answer.

My staff and I were working an evening shift when we received a call from a dispatcher. An ambulance was $10 \mathrm{~min}$ out bringing in an elderly man VSA-vital signs absent. I watched as staff grabbed gowns and masks and prepared the room for a protected code blue. The man was wheeled in on a stretcher, with paramedics actively performing CPR. He was transferred to a hospital bed, and a timer was started. I

Rheanna Bulten

rheanna.bulten@medportal.ca

1 Michael G. DeGroote Centre for Learning and Discovery, McMaster University, Hamilton, ON, Canada recognised the ACLS protocol for pulseless electrical activity being followed, with the emergency physician leading. After 25 min of compressions and epinephrine, in addition to more than $40 \mathrm{~min}$ of resuscitation prior to arrival, the emergency physician paused.

"Do we have a pulse?"

"No pulse."

"Ok, I'm going to call it, does everyone agree?"

Of course, no one on the team wants to stop a code if there is any chance of saving a patient. No one wants to give any less than their utmost 100 percent effort to save whoever can be saved. We are not trained to give up, and nor do we want to. But here in this moment, I wondered-at what point during a code do the scales tip from beneficence to maleficence? When are extraordinary measures no longer in keeping with what a patient would want for themselves? When do we apply our clinical judgement regarding what a patient can reasonably survive?

The code progressed to "Time of death..." and a somberness fell over the room. Nursing staff and respiratory therapists begin picking up equipment off the floor and wiping surfaces that caught blood splatters. My staff and I meet in the hallway and start walking to talk to the family. In a quiet room off to the side of the emergency department, I clearly saw the feedback loop of our algorithm collide with grief. I saw the fine line we dance in the emergency department of doing everything we possibly can for a patient, and finally facing the sadness and finality of allowing a patient to pass. When we delivered this news, the family asked us, "what did you do for him? Could he have come back? Are you sure?" We told this family with confidence we had done everything we possibly could, and I believe that is true. But sitting there in my blue scrubs holding a box of tissues for our patient's wife, I wondered if calling time of death is sometimes a grey area. Do we push for another round of compressions if a toddler is on the table? When do we decide that providing help no matter what is no longer the right answer? When should we say, "let them go, the CPR is breaking their ribs, they cannot come back..."? How do we sit with a family in their 
grief and offer reassurance, with any real sense of confidence that we truly did everything we could? I believe these difficult moments represent the science of medicine interacting with the art of medicine-a combination of medications and evidence, humanity and uncertainty, all mixed together in a moment of leadership, "does everyone agree? Have we done all we can?".

I am grateful that in some emergency circumstances, there is a clear path forward, and we can provide a measure of comfort to families. Maybe our rules and algorithms offer some peace for those of us making decisions in a code that we did all we were able to-that we did the right thing. Maybe there are not any answers at all. Officially, ACLS protocol states "consider termination of resuscitation" when certain clinical criteria are met for calling time of death, and sometimes patients do survive cardiac arrests. But emotionally navigating these spaces, in the words of Paul Kalanithi, is necessarily both a biological and philosophical exercise. 